\title{
Disease Response Completion Status
}

National Cancer Institute

\section{Source}

National Cancer Institute. Disease Response Completion Status. NCI Thesaurus. Code C117402.

A term used to describe the state or condition of the completeness of the disease response data. 